\title{
Percentage of Ki-67 Positive Nuclei
}

National Cancer Institute

\section{Source}

National Cancer Institute. Percentage of Ki-67 Positive Nuclei. NCI Thesaurus. Code C160485.

A quantitative measurement of the percent of nuclei that are positive for expression of antigen Ki-67 compared to the total number of nuclei in a sample. 